\title{
Landscape as Connecting Link of Nature and Culture: Spatial Planning Policy Implications in Greece
}

\author{
Stella Sofia Kyvelou $1, *,+\left(\mathbb{C}\right.$ and Anestis Gourgiotis ${ }^{2,+}$ \\ 1 Department of Economic and Regional Development, Panteion University of Social and Political Sciences, \\ 136, Syggrou Ave., 17671 Athens, Greece \\ 2 Department of Planning and Regional Development, University of Thessaly, 38334 Volos, Greece \\ * Correspondence: kyvelou@panteion.gr; Tel.: +30-6945-112323 \\ + These authors contributed equally to this work.
}

Received: 19 June 2019; Accepted: 25 July 2019; Published: 27 July 2019

\begin{abstract}
The research paper investigates the diverse understandings of "landscape", along with demonstrating the modes of contribution of the European Landscape Convention (ELC) of the Council of Europe (CE) in influencing national spatial planning systems. The paper, interested in considering the efficiency of landscape policy from a territorial perspective, briefly outlines the perception and understanding of landscape as connecting link of nature and culture and conducts a literature review with the aim to support the prospect of a «European model of landscape planning». Lastly, it critically examines the approach to landscape planning and management by the Greek state, revealing the catalytic role of the Council of Europe (CE) in activating the dimension of landscape in Greece, in a mutualistic perspective between environmental policy and spatial planning, mainly through strategic spatial planning tools (i.e., the Regional Spatial Plans, RSPs). The results point out that (a) the ELC gave new impetus to spatial planning in Greece, providing the tool to manage and coordinate landscape policy, positively influencing the evolving spatial planning paradigm; (b) the decentralized approach adopted, identified landscapes of particular value at a regional level, so as to be given priority in terms of the implementation of coordinated governance arrangements and management actions. However, the implementation of landscape policy continues to rely on the underlying spatial planning level (Local Spatial Plans, Special Spatial Plans) and a general conclusion is that both on land and on sea, it depends on the incorporation of evolutionary trends in planning including an evolutionary perspective for landscape itself, viewed as a complex social-ecological system.
\end{abstract}

Keywords: landscape; spatial planning; nature; culture; European Landscape Convention; evolutionary planning; Greece

\section{Introduction}

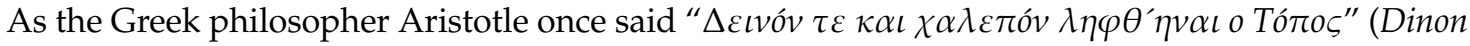
te kai chalepon lifthine o Topos) which means that it is extremely difficult to perceive the meaning of Place. This is also valid for the concept of Landscape.

The word "landscape" (landscap in Middle Dutch, landschaft in German, landskap in Old Norse, landskip in a previous formation in English) appeared in English in 1603, designating a "settler's clearing in the forest with animals, huts, fields, and fences" [1-3]. "Landscape" initially meant a man-made construct and the intrinsic cultural values and practices [4].

Furthermore, Leser in 1997 [5] defined landscapes as ecosystems, i.e., composite systems of biotic (including humans) and abiotic elements. Nowadays, the shared understanding of "landscape" complies with and often derives from the definition of the European Landscape Convention (ELC, 2000) as "an area, as perceived by people, whose character is the result of the action and interaction of natural 
and/or human factors". This definition is compatible with the landscape theory shift to a cultural-based approach of the landscape [2], which explicitly condemns the idea that landscape, is a view, scenery, or an object that remained unaltered over the ages. The perception of landscape as embraced by the European Convention echoes also the idea of landscape as a social construction. This new paradigm considers landscape as a social product that is the cultural projection of a society in a particular territory from a tangible, intangible and symbolic viewpoint.

The ELC also emphasizes the fact that the human component of landscape does not necessarily impact on ecosystems or on natural capital, but also includes people's contributions either emotional and intellectual or socioeconomic and cultural, adding, in diverse ways, in building landscape uniqueness and diversity [6]. This consideration is at the opposite of the dualistic view [7] and adopts an interactive mutualistic approach [8] that considers humans and nature as sharing the entire landscape. In other words, the "biodiverse cultural landscape" is a mutualistic arrangement [7]. Landscape is meant as the human component of the environment, mostly referring to the cultural features and land uses. Therefore, the notion of "landscape" can be used to indicate networks of people, tangible and intangible associations between humans and places, interactions between people and communities in their environment or simply, between nature and culture. It is obvious that cultural features emphasize the holistic view of landscapes since humans interact with landscapes in vibrant transactional procedures [9]. Cultural landscapes are an amalgam of nature and culture, tangible and intangible heritage, biological and cultural diversity, embodying a thoroughly inter linked framework of relationships, the quintessence of culture and identity, as evoked by Rössler [10].

Consequently, landscapes and specifically cultural landscapes can be comprehended as social-ecological systems, in which economic, environmental and social constituents are closely interlinked [11]. It is noteworthy that many landscape studies have embraced holistic attitudes, integrating approaches from both natural, social and human sciences, as well as local knowledge in a transdisciplinary and interdisciplinary manner [12]. According to Vos and Meekes [13], landscape research should raise the interdisciplinary and multidisciplinary and adopt different temporal and territorial scales, involve decision-makers and cooperate with landscape users, include links between landscape evolution and human understanding and satisfaction, and improve the knowledge of the various social and economic procedures that configure landscapes. Besides, more recently, there has been a remarkable focus in the literature, on the role that natural ecosystems have in human well-being through the concept of ecosystem services. However, despite the increasing interest in ecosystems thinking and the voluminous ecosystem services research, considering landscape and related decision-making through the concept of ecosystem services is not yet apparent [8].

This research paper is interested in examining the efficiency of landscape policy from a territorial perspective, embedding in the territory, landscapes as social-ecological systems with natural and cultural features fully interwoven.

Thus, it is structured around three main axes:

a. The different perceptions and understandings of landscape highlighting the consideration of landscape as social-ecological system, between nature and culture.

b. The way that this consideration of landscape, adopted by the European Landscape Convention, in combination with the overall evolution of our understanding of conservation [14,15], has influenced the integration of landscape planning in different policy sectors and especially in spatial planning which by definition concerns human intervention on the natural environment. This is approached through a literature-based investigation concerning European and non-European countries.

c. A critical investigation of the approach to landscape planning and management by the Greek State, identifying key issues addressed in the landscape policy and revealing the catalytic role of the Council of Europe (CE) in activating the dimension of landscape in Greece, in a mutualistic perspective between environmental policy and spatial planning, primarily through strategic planning tools. In this context, a brief presentation and relevant criticism are developed 
on the methodology and the governance system adopted for the incorporation of landscape considerations in spatial planning, focusing on the implementation-related shortcomings.

\section{Materials used and Methods of Assessment}

This research firstly makes use of the European Landscape Convention [16] and relevant reports from the Council of Europe workshops. The Information System of the Council of Europe Landscape Convention was another source, for the assessment of the extent of its application by the Council of Europe countries. Furthermore, a literature review was conducted of selected papers from the voluminous landscape research and mainly from the research that takes into account the ELC and its differentiated impact in different countries according mainly to spatial planning culture and the local governance system [17].

On the other hand, for analyzing the Greek case-study, an assessment of existing regulations and the so-called Regional Spatial Planning Frameworks (RSPFs)is made. Through the updating of the RSPFs, a regional landscape policy-for the 12 out of 13 administrative regions of Greece-was launched as a strategic approach that regulates, adjusts and determines the development of each Region taking into account economic, social, cultural, residential and environmental prospects.

In 2016, a new law (4447/2016) renames the Regional Spatial Planning Frameworks (RSPS) to Regional Spatial Plans (RSPs) and the landscape planning methodology adopted by the new Plans (RSPs) consists of the four steps outlined below [18]:

1. Current situation assessment: Location and recording, using a scale of $1: 250,000$ of a series of elements including, but not limited to, landscapes of particular natural beauty ("Topia Idiaiterou Fysikou Kallous-TIFK), archaeological sites, traditional settlements, monuments and historical sites, etc.;

2. Identification and description of the Landscape Zones of each Region: A "Landscape Zone" is defined as an area identified and demarcated on the basis of its distinct personality, taking into account geomorphology and the elements that characterize it. A Landscape Zone is characterized by a dominant function or element (a lake, gorge etc.), which however may extend to neighboring areas with which there is functional spatial dependence;

3. Assessment and demarcation of Landscape Zones: Based on the data from the previous stage and on-site research, a minimum of four (4) types of Landscape Zones have been defined for each Region: a. Landscape of International Value; b. Landscape of National Value; c. Landscape of Regional Value; d. Particularly Degraded Landscape.

Indicatively, the landscape maps for the Regions of Macedonia-Thrace, Crete and Peloponnese are listed, in Figures 1-3, below. Each map identifies for each region the Landscape Zones of International, National and Regional Value and those designated as Particularly Degraded landscapes. Then, for each of these landscapes, a set of policy guidelines for landscape management is addressed.

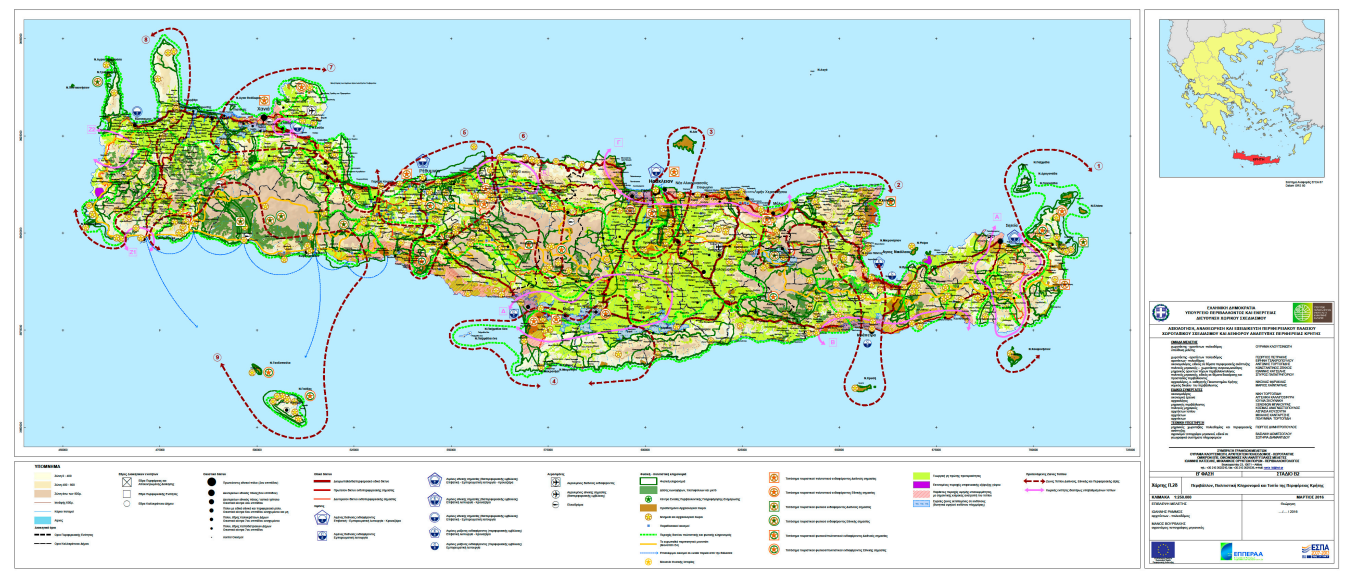

Figure 1. Landscape map of the Region of Crete. 


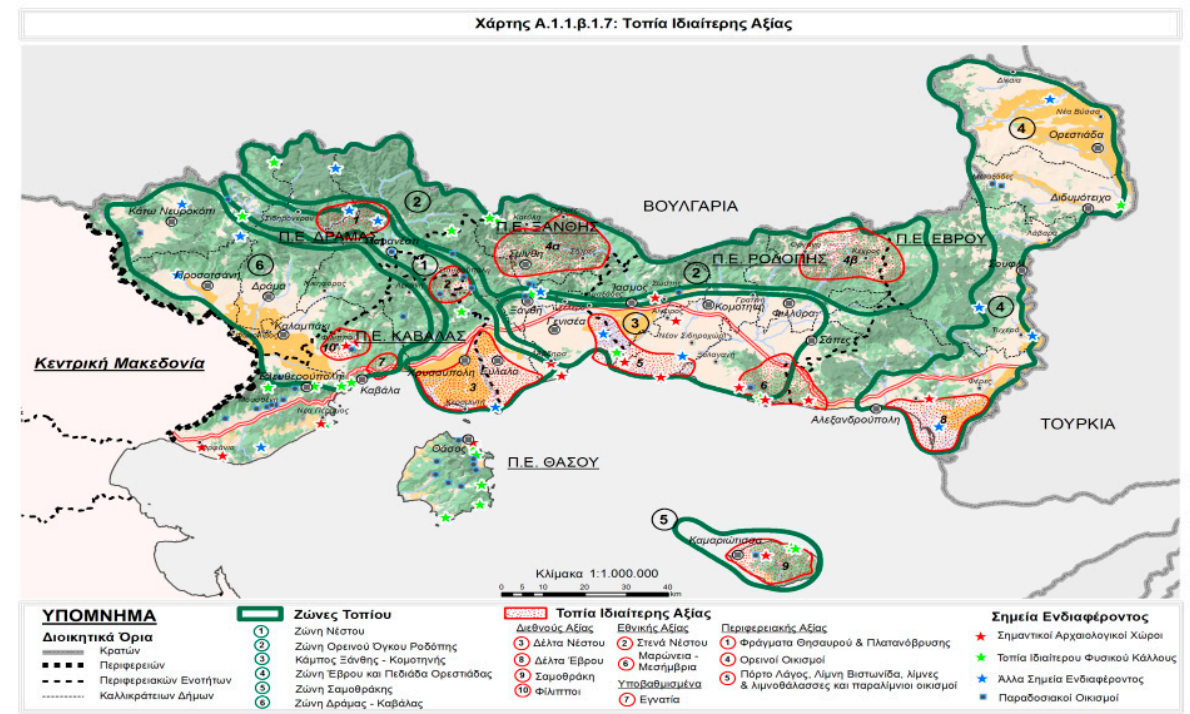

Figure 2. Landscape map of the East Macedonian and Thrace Region, source: Ministry of Environment and Energy, Revision and evaluation studies of Crete and East Macedonia -Thrace Regional Spatial Plans accordingly, 2016.

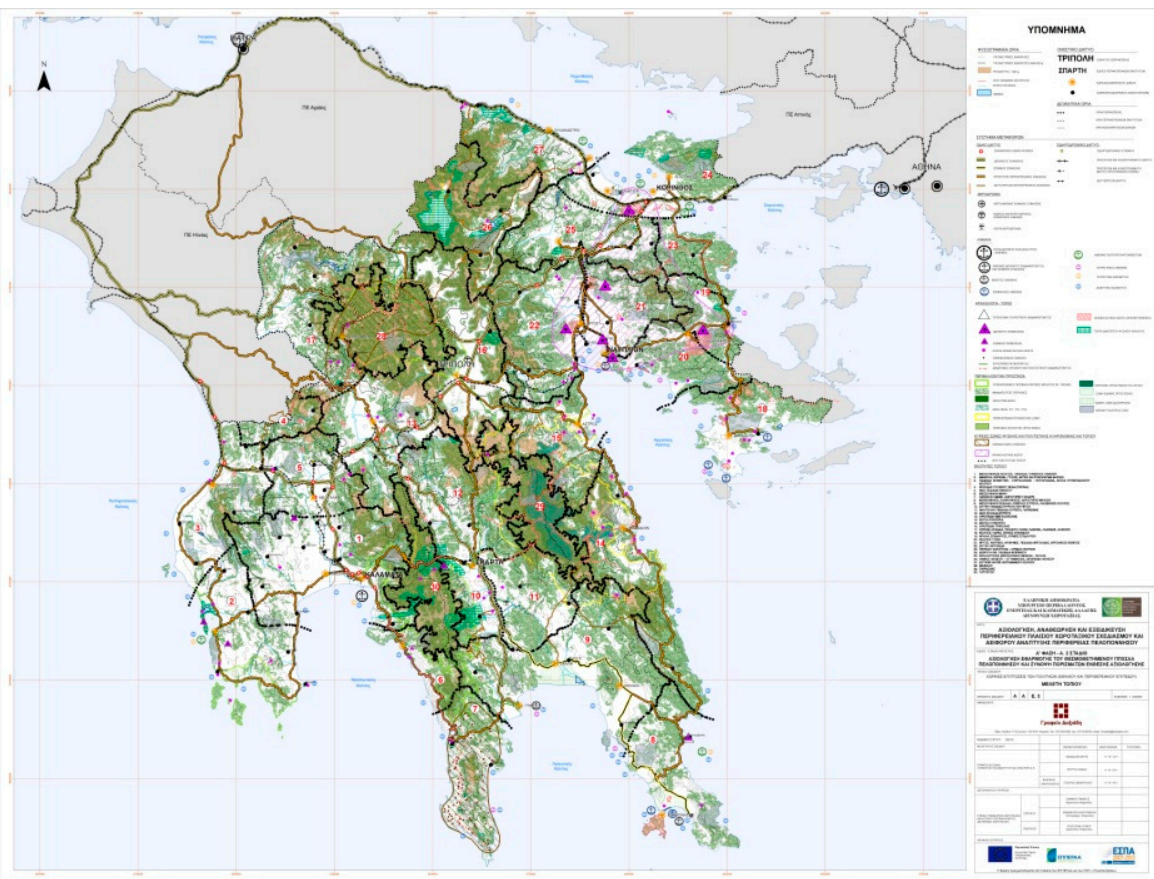

Figure 3. Landscape map of the Peloponnese Region, Source: Ministry of Environment and Energy, Revision and evaluation study of Peloponnese Regional Spatial Plan, 2016.

The Table 1 below summarizes the results of the landscape assessment in these three regions.

Table 1. Number and category of landscapes, in the three Greek regions mentioned above.

\begin{tabular}{ccccc}
\hline Regions & $\begin{array}{c}\text { Landscape of } \\
\text { International Value }\end{array}$ & $\begin{array}{c}\text { Landscape of } \\
\text { National Value }\end{array}$ & $\begin{array}{c}\text { Landscape of } \\
\text { Regional Value }\end{array}$ & $\begin{array}{c}\text { Particularly Degraded } \\
\text { Landscape }\end{array}$ \\
\hline Region of Crete & 11 & 17 & 9 & 7 \\
\hline $\begin{array}{c}\text { Region of East } \\
\text { Macedonia and Thrace }\end{array}$ & 4 & 3 & 3 & 1 \\
\hline Region of Peloponnese & 14 & 20 & 20 & 1 \\
\hline
\end{tabular}


Regional landscape policy also gives specific directions to the underlying local level, that is to the Municipalities and this is of great importance for a country where local planning is either completely lacking or is deficient. The assessment of the above Landscape Zones was accompanied by a detailed description comprising a number of elements including, but not limited to, the particular features of landscapes which require conservation and management, their attractiveness in terms of the number of visitors, the identification and description of pressures, etc. The individual landscapes per Landscape Zone were selected according to their value. The classification of landscapes into 'International', 'National' and 'Regional' was always based on the following criteria: (1) aesthetic and natural beauty, (2) representativeness, (3) recognition, (4) natural character, (5) existing recognized protected elements, (6) value of landscape as a natural resource, and (7) uniqueness-rarity. These criteria are in accordance with the standards issued by the competent authority (Ministerial Decree 10106/2011 "Approval of specifications for the drawing up of the Regional Frameworks for Spatial Planning and Sustainable Development" and were subjected to scholars', local authorities' and Regional Councils' individual judgment, through a consultation process. However, as it emerges from the approaches to landscape management in Regional Spatial Frameworks in Greece, planners are hesitating to follow a homogeneity based on the above specifications, which is certainly justified by the subjective criterion of scholars and the regional and local differentiation (primarily geophysical).

The classification of the landscape in one of the types mentioned above (of International, National or Regional Value or degraded landscapes) is made combining these criteria. Assumptions are made e.g., whether a landscape zone has five out of the seven criteria then it is classified to the Landscapes of International Value. Accordingly, if it fulfils four out of seven criteria, it may be classified to the Landscapes of National value etc.

4. Policy directions and priorities for each Landscape Zone for each Region separately: These guidelines provide policy priorities that guide strategic landscape planning on the regional level and the underlying planning as well (Local Spatial Plans, Special Spatial Plans, Athens Master Plan etc.)

\section{Results}

\subsection{A Literature Review about Landscape Policy from a Territorial Perspective}

The European Landscape Convention (ELC), adopted by the Council of Europe, is one of the most important conventions of international law on the landscape, fully devoted to it and to its protection. The ELC aims to promote, protect, manage and plan European landscapes and the international co-operation in this area and covering all the dimensions of landscape, suggested an environmental and territorial perspective of the concepts of landscape protection and management [19]. It introduces a pan-territorial application, covering natural, rural, urban and peri-urban areas and gives value to all types of landscape: outstanding, commonplace or deteriorated ones. In the light of the landscape, culture and nature, the Council of Europe sets as its primary objective the promotion of quality of life and prosperity in sustainable development. Roe [20] argues that the ELC adopts a pioneering approach offering a holistic understanding of landscape combining sustainability thinking and social-ecological considerations-or culture and nature - and that it represents revolutionary thinking regarding the value of the term of 'cultural landscape'. Several researchers [17,21,22] investigated the effects of incorporating the ELC into national landscape planning contexts. The ELC implementation depends, as de Montis [17] proved, on historical governance arrangements and national attitudes and mentalities related to land planning. Through a qualitative comparative analysis between Mediterranean (Spain, France, Italy) and non-Mediterranean contexts (Switzerland, Netherlands, UK) and with a concern to explore the possibility of a "European model of landscape planning" [17] and also of a monitoring system of the ELC implementation on national level, De Montis [17] demonstrated the impact of the ELC in planning practices and identified positive influences even if the contexts are very different. He distinguished diverse contexts such as constitutional provisions for the protection of the landscape, specific regulations, specific laws for the landscape, an extension of the existing legislation to include 
operational tools able to foster local landscapes etc. It is noteworthy that in the Mediterranean countries (Italy, Spain and France), landscape conservation and management is also considered as an asset for regional development. This is also the view of the European Observatory for Territorial development and Cohesion (ESPON) project LIVELAND Liveable Landscapes: A key value for sustainable territorial development [23].

Another issue revealed in the literature is the evaluation and assessment to identify landscape planning needs. The background for landscape assessment, focusing on multiple variables, is widely used in England and Scotland [24]. In other cases, landscape mapping (atlases) has allowed the creation of a common "dialect", a common terminology on landscape issues, thus helping the competent authorities in the decision-making regarding the management and protection of the landscape [25]. Besides, in Spain (Catalonia), the Netherlands, and France, the landscape is monitored by a structured system of landscape observatories [26].

The importance of the relationship between spatial planning and landscape policies is clearly established in the Convention, as evidenced through the direct references to the activity of spatial planning contained in the ELC text and in the Explanatory report. Furthermore, Zoido-Naranjo [27] explains that the scope of the Convention, which covers the parties' entire territory, "makes territory the common subject of spatial planning and landscape policies". Additionally, de Montis [17] states that the ELC spots a transition towards a territorial and environmental perspective of the notion of landscape and the associated actions of landscape protection, management and planning. As outlined in the preceding section, each Party to the Convention is likely to apply the ELC as a supranational treaty according to its own legal order and governance arrangements, in agreement with the principle of subsidiarity (see CoE, 2000a: II. 4). In relation to this, the ELC presents landscape as essentially an element of public administration to be treated as "a territorial project" [28]. Nevertheless, the multi-functionality of the landscape resource together with the diverse relations that people have towards the 'perceivable' environment, make the protection, planning and management of landscape a challenging process. Hence, the inherent complexity of the landscape phenomenon presents major challenges across the European territories, regarding both the governance of the landscape resource as a process of spatial planning and in relation to the formulation and implementation of territorial policies anchored within the legal framework for the ELC.

Landscape has come to be viewed as both a natural and cultural resource with a strong appeal to society and a medium through which sustainable development programs can be pursued in the future [29]. In relation to this, Selman [30] claims that through the issue of the ELC, landscape has come to be recognized more closely interwoven with the key concerns of spatial planning. Furthermore, as a consequence of the formulation of the ELC, Déjeant-Pons [16] contends that the status of landscape as a spatial planning issue was prioritized and regarded as increasingly crucial to issues of sustainability and place-making across the European model of society. Moreover, Selman [30] and Kidd [31] both present valuable insights into the origins and evolution of landscape planning, from a European perspective. Selman [30] conceptualizes landscape as an "integrative framework", given that it concentrates numerous features of sustainable development and places the consideration of landscape personality, distinctiveness, attractiveness and resilience at the core of placemaking and the integration of various planning purposes. Kidd [31] explains how both landscape and spatial planning approaches converge to the "integrative planning" so as to proceed to more sustainable patterns of development. However, she stresses the role of the many professionals and groups in adopting the foresight of landscape planning if this is to reveal its full potential.

The ELC, launched and signed in Florence in 2000, was ratified by the majority of member states and has predisposed the evolution of both theory and practical implication of common principles (Council of Europe, 2006). In this way, 15 years later, De Montis [17] concludes that the great percentage of devotion to the ELC and the level of cohesion in adopting certain tools is encouraging and may lead to the perspective of a "European model of landscape planning". Accordingly, Brunetta and Voghera [32] emphasize the necessity of innovative ideas and schemes in the procedures of the ELC application 
regarding the landscape definition, assessment and principles. Furthermore, from an educational perspective, Herlin [33] claims that the broad concept of landscape introduced by the ELC in spatial planning raises the idea of higher education innovative teaching with a holistic approach.

The following tables, building on data coming from the Information System of the Council of Europe Landscape Convention, summarize firstly the institutional acknowledgment of landscape and landscape planning and the consequent administrative levels endowed with landscape responsibilities (Table 2) and secondly, in a series of countries, the different policy sectors that are already endowed with landscape considerations (Table 3).

Table 2 shows that in the majority of the cases, landscape planning constitutes a State responsibility and no specific laws were issued with the exemption of Greece, France and Portugal. Through Table 3, it is, besides, evident that "spatial and regional planning" and "environmental policy" sectors are the main policy sectors where landscape considerations are well installed. The "cultural heritage" and "sustainable development" policy sectors follow, in the majority of the countries examined. This finding reaffirms the environmental and territorial interpretation and perspective of the landscape concept, as expressed by the ELC and adopted by the different member states. 
Table 2. Institutional recognition of Landscape and landscape planning, levels with landscape responsibilities and contents.

\begin{tabular}{|c|c|c|c|c|c|c|c|}
\hline COUNTRIES & $\begin{array}{l}\text { Administrative } \\
\text { Entity }\end{array}$ & $\begin{array}{l}\text { Compliance of } \\
\text { Landscape } \\
\text { Planning } \\
\text { definition to the } \\
\text { ELC } \\
\end{array}$ & Specific Law & $\begin{array}{c}\text { Landscape } \\
\text { Policies Based on } \\
\text { the ELC }\end{array}$ & $\begin{array}{l}\text { Requirement of } \\
\text { Landscape by } \\
\text { Law/Regulation }\end{array}$ & $\begin{array}{c}\text { Official Process } \\
\text { for Landscapes } \\
\text { Identification and } \\
\text { Administrative } \\
\text { Level }\end{array}$ & $\begin{array}{l}\text { Contents of System Used } \\
\text { to Identify Landscape }\end{array}$ \\
\hline ANDORRA & State level & YES & No & $\begin{array}{l}\text { National } \\
\text { Landscape } \\
\text { Strategy }\end{array}$ & No & No & $\begin{array}{c}\text { National level (Maps/GIS/ } \\
\text { Photographs) }\end{array}$ \\
\hline BELGIUM-WALLONIE & Region & YES & No & No & No & $\begin{array}{l}\text { YES (regional } \\
\text { level) }\end{array}$ & Maps/GIS/Photographs \\
\hline FRANCE & $\begin{array}{c}\text { State } \\
\text { Territorial } \\
\text { communities }\end{array}$ & YES & YES & YES & $\begin{array}{l}\text { YES-reference to } \\
\text { Landscape Atlases } \\
\text { and Landscaping } \\
\text { Quality Objectives }\end{array}$ & $\begin{array}{l}\text { Regional } \\
\text { Local }\end{array}$ & $\begin{array}{c}\text { Atlas de paysages } \\
\text { State and local authorities }\end{array}$ \\
\hline GREECE & State level & YES & YES & YES & YES & $\begin{array}{l}\text { Yes (regional } \\
\text { spatial plans) }\end{array}$ & Regional level Maps \\
\hline HUNGARY & State level & YES & No & No & No & No & - \\
\hline MONTENEGRO & $\begin{array}{c}\text { State level } \\
\text { Municipal level }\end{array}$ & YES & No & No & No & No & $\begin{array}{l}\text { Ministry of sustainable } \\
\text { development } \\
\text { Maps/GIS/Photographs }\end{array}$ \\
\hline NORWAY & State level & YES & No & YES & No & No & - \\
\hline POLAND & State level & YES & No & No & YES & $\begin{array}{c}\text { YES } \\
\text { (at regional level) }\end{array}$ & $\begin{array}{l}\text { Regional level } \\
\text { GIS }\end{array}$ \\
\hline PORTUGAL & State level & YES & YES & YES & No & No & - \\
\hline SERBIA & $\begin{array}{c}\text { State level, } \\
\text { Provincial level } \\
\text { Regional Level }\end{array}$ & YES & No & YES & YES & No & $\begin{array}{c}\text { Regional level } \\
\text { Maps/GIS/Photographs/3D }\end{array}$ \\
\hline SLOVENIA & $\begin{array}{c}\text { State Level } \\
\text { Local Municipal } \\
\text { level }\end{array}$ & YES & No & YES & No & No & $\begin{array}{l}\text { National level } \\
\text { Maps } \\
\text { Photographs }\end{array}$ \\
\hline TURKEY & State level & YES & No & No & YES & No & $\begin{array}{l}\text { Ministry of Forestry and } \\
\text { Water Affairs } \\
\text { Maps/GIS/Photographs/3D }\end{array}$ \\
\hline
\end{tabular}


Table 3. Different policy sectors integrating landscape considerations, in a series of the Council of Europe countries.

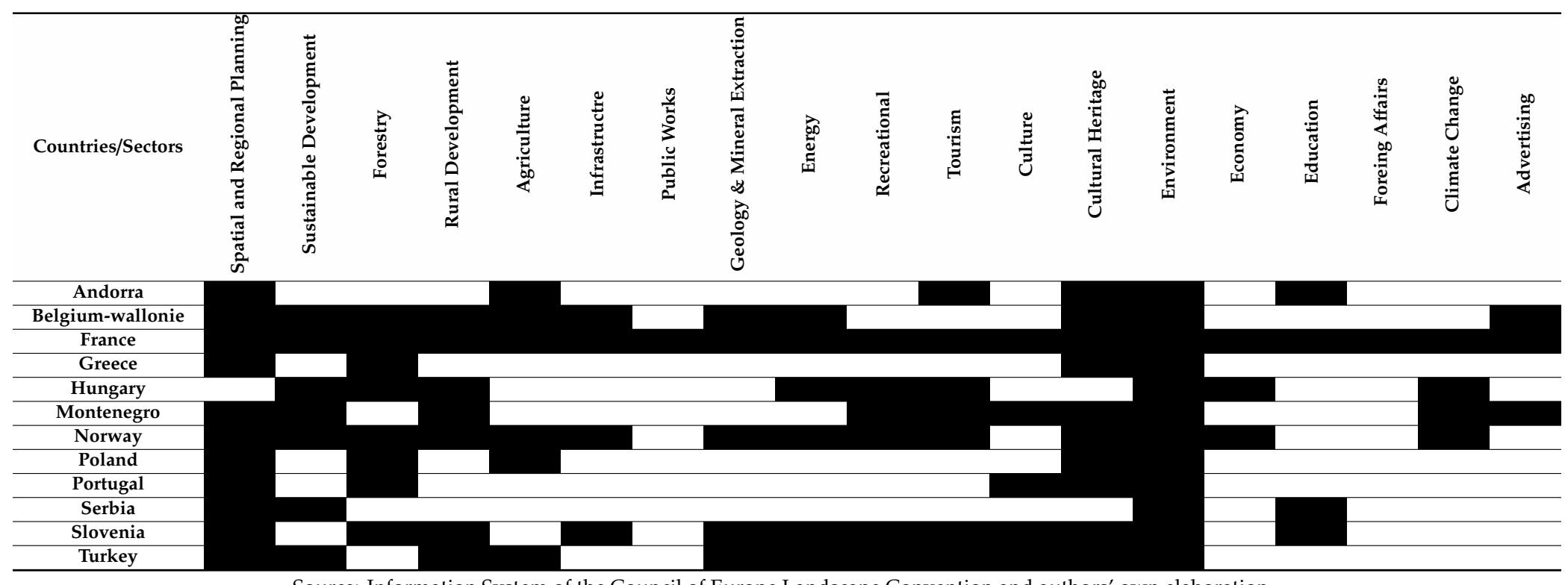

Source: Information System of the Council of Europe Landscape Convention and authors' own elaboration. 


\subsection{Greek Landscapes, between Nature and Culture}

Europe has a lifelong, widespread, and extensive history of land-use by its inhabitants. Its thorough territory can be considered as a patchwork of often fragmented natural and cultural landscapes, in which different periods of human impacts were expressed and overlapped, thus forming multi-layer systems. Located in the Eastern Mediterranean, Greece is characterized by a significant historical and cultural heritage, as well as by rich ecosystems in fragile balance-natural and man-made features that create spaces of particular value and landscapes of considerable variety. The surrounding Mediterranean basin is a very special natural-geographic space, a background for the many multicultural societies which have prospered there through the years.

The peculiarities, the complexity and the beauty of these spatial and social formations were a source of inspiration for many of the 18th and 19th century travelers, who sought to memorialize them in their writings, poetries or paintings [34]. A typical example, in this respect, are the words of the French author Jacques Lacarrière, who travelled for many years in the Mediterranean Sea and particularly in Greece and who, speaking of the Greek islands in his writings, portrayed the landscapes that he encountered as places "...of rare perfection and sensitivity (paysagesexquis)" [35].Until the mid-20th century, rural life in the countryside was what defined Greek reality, and landscape was mostly the result of the spatial organization of the cultivation systems. The landscape traditionally adapted to local socio-economic structures, often governed by the locally diversified power relationships between the different families and social groups and to a great extent was influenced by the action of indigenous people and communities, their values and knowledge, their means of production and the technology they used. The abrupt adjustment of the countryside to the requirements of modern agriculture and of the rural exodus that contributed to a large-scale and often unplanned and illegal urbanization, further exacerbated by the deportation of refugees from Asia Minor during the 1920s, brought about widespread and rapid changes in the evolution of landscapes, both rural and urban, leading to their degradation [36].

Faced with this drastic change of the landscape during the last fifty years, and given that modern trends did not manage to articulate a distinct place identity, the Greek landscape seems to be defined mainly by the lack of historical ties, its constant updating and its ability to not only destroy but also create innovative formations according to some anarchic and random logic. Indeed, the participation of time and of the human presence in the evolving landscape dynamics is a presumption of cultural value. This was, besides, well expressed by Pikionis [37], who wrote that "...we are studying the spirit which emanates from each particular land or place.", thus confirming the cultural and spiritual dimension of landscape ensuing from the direct human presence in its reproduction through time. However, according to Latarjet and Hers [38], "facedwith landscapes which have lost their cohesion and value, or they are no more than remnants of old values, creative work is required to give meaning to such a state of affairs". In this sense, the representation of the modern Greek landscape requires new "reading" and interpretation: not only for documentation reasons, but mainly as a creative enterprise to give meaning to, and construct, in a balanced way, a landscape identity respecting natural and cultural heritage but also able to maintain and provide people with ecosystem services, now and into the future. The instability of the Greek landscape, therefore, results in the search for precision and for the sense of permanence, driven by the logic of a technical, artistic formalism totally at odds with the reality it illustrates [35].

\subsection{The Institutional Approach to Landscape in Greece}

The Greek legal system had long responded to the need to respect nature, not only in the sense of the natural environment (fauna, flora, forest vegetation, geomorphological formations), but also with aesthetic and cultural aspirations (aesthetics, mental health, inspiration, enjoyment and rest), as well as for social and economic reasons mainly related to territorial attractiveness and tourism. Protection is derived from the Constitution as well as from common law (Table 4), starting as early as in 1938 with the so-called "Emergency Law n.856". Later on, in the beginning of the 50s, the concept of 
places or works "characterized as landscapes of particular natural beauty" ("Topia Idiaiterou Fysikou Kallous-TIFK") was introduced (law 1469/1950) providing for them a protection status in accordance with the provisions of the Archaeological Code (Law 1469/1950). Subsequent additional legislation adopted two new categories of protected areas, namely "aesthetic forests", and "listed monuments of nature" [39]. Moreover, the Constitution of 1975-1986/2001 gave new impetus to the protection of the environment, establishing it as a value protected by the Constitution and an obligation of the State. In alignment with the constitutional mandates and with the new emerging perceptions, two laws namely the law "On the protection of the environment" (1650/1986) and later the law on the "Conservation of biodiversity" (3937/2001) approached the concept of the environment as "all natural and man-made factors and elements which interact between them and affect the ecological balance, quality of life, health of local residents, historical and cultural traditions and aesthetic values." (Table 4). The first one recognized the protection of the environment as "a fundamental and integral part of the cultural and development process and policy", and introduced a special protective status applied to areas, individual elements or formations of nature and landscape, "on account of their ecological, geomorphological, biological, scientific or aesthetic significance" [39].

Table 4. Milestones related to the integration of landscape planning in the Greek legal system. Source: authors' own elaboration.

\begin{tabular}{|c|c|}
\hline 1938 & $\begin{array}{l}\text { Constitutional provision as well as from common law (Emergency Law 856) for the } \\
\text { protection of natural and cultural heritage. }\end{array}$ \\
\hline 1950 & $\begin{array}{l}\text { - Law 1469/1950 about landscapes of particular natural beauty ("Topia Idiaiterou Fysikou } \\
\text { Kallous-TIFK") provides for them a protection status in accordance with the provisions of } \\
\text { the Archaeological Code (Law 1469/1950). } \\
\text { - Subsequent additional legislation adopts two new categories of protected areas, namely } \\
\text { "aesthetic forests", and "listed monuments of nature" }\end{array}$ \\
\hline 1975 & $\begin{array}{l}\text { The Constitution of 1975-1986/2001 gives new impetus to the protection of the environment, } \\
\text { establishing it as a value protected by the Constitution and an obligation of the State. }\end{array}$ \\
\hline 1986 & Issue of Law 1650/1986 on the protection of the environment \\
\hline 1999 & $\begin{array}{l}\text { Law 2742/1999 "Spatial planning and sustainable development" implies a definition of the } \\
\text { landscape. }\end{array}$ \\
\hline 2001 & Issue of Law 3937/2001 on the conservation of biodiversity \\
\hline 2008 & $\begin{array}{l}\text { General Framework for spatial planning and sustainable development (Law 2742/99) } \\
\text { acknowledges the real estate and intense housing development threats to the landscape. }\end{array}$ \\
\hline 2008 & $\begin{array}{l}\text { Special Frameworks for RES, Tourism, and Industry set out the need to establish a } \\
\text { landscape policy }\end{array}$ \\
\hline 2010 & Ratification of the European Landscape Convention by Law 3827/2010 \\
\hline 2014 & $\begin{array}{l}\text { Assignment of the competent authority for the preparation and implementation of the } \\
\text { national policy on the landscape (Ministry of Environment and Energy) }\end{array}$ \\
\hline 2018-2019 & Embedment of Landscape planning to Regional Spatial Plans for 12 Greek regions \\
\hline 2018 & $\begin{array}{l}\text { Law } 4546 / 2018 \text { on Maritime Spatial Planning makes reference to coastal landscapes, linking } \\
\text { with Integrated Coastal Zone management (ICZM) }\end{array}$ \\
\hline
\end{tabular}

It is thus evident, that in Greece, the landscape was originally integrated into environmental planning without any interconnection with the spatial planning realm, ignoring that spatial plans directly affect a multitude of quantitative and qualitative factors of the natural and man-made environment. The choice, due to the great extent of the dichotomy between environmental policy and planning still valid in the country, was to adopt an autonomous framework of tools and actions for the environmental components, independent of that of the spatial components, without direct interconnection and interdependence. The cooperation between environment and spatial planning authorities was usually occasional. The inevitable consequence was the ineffectiveness of the measures 
adopted, the gap between legal commitments and their implementation, but often circumvention and failures in monitoring and controlling the implementation [39].

Only since 2014(see Figure 4 and Table 4), landscape policy becomes a spatial planning related responsibility with the assignment of the Spatial Planning Department of the Ministry of Environment-currently the Ministry of Environment and Energy - as the competent authority for the preparation and implementation of the national policy on landscape. However, despite the political will, the spatial planning legislation addresses landscape management and landscape policy in a restricted way. Whilst law 2742/1999 "Spatial planning and sustainable development" issued to harmonize national spatial planning policy with the European Spatial Development Perspective (ESDP) framework, through the stated objective of spatial planning, "to protect and restore the environment, conserve the ecological and cultural reserves, and promote the comparative geographic, natural, productive and cultural assets of the country" implied, indirectly, a definition of the landscape [40], the most recent law 4447/2016 "Spatial Planning-Sustainable Development" (Figure 4) does not make specific and explicit reference to the landscape nor does it foresee any mechanisms for the implementation of the landscape policy. Only a simple reference to "...[the] protection of the cultural and natural landscape" is made in the provisions concerning the Special, Regional Spatial Planning Frameworks and the Local Spatial Plans, thus addressing landscape as part of these three levels of spatial tools (Figure 4).Similarly, in the law 4546/2018 enacting the integration into Greek legislation of the Maritime Spatial Planning Directive (2014/89 /EU), no guidance is given either for the management of the marine (seascapes) or the coastal landscapes. However, an indirect reference is made through the mention to the definition of "Integrated Coastal Zone Management" (ICZM) that is described as " ... a dynamic process for the sustainable management and use of coastal zones, while taking into account the fragile nature of coastal ecosystems and landscapes... “.

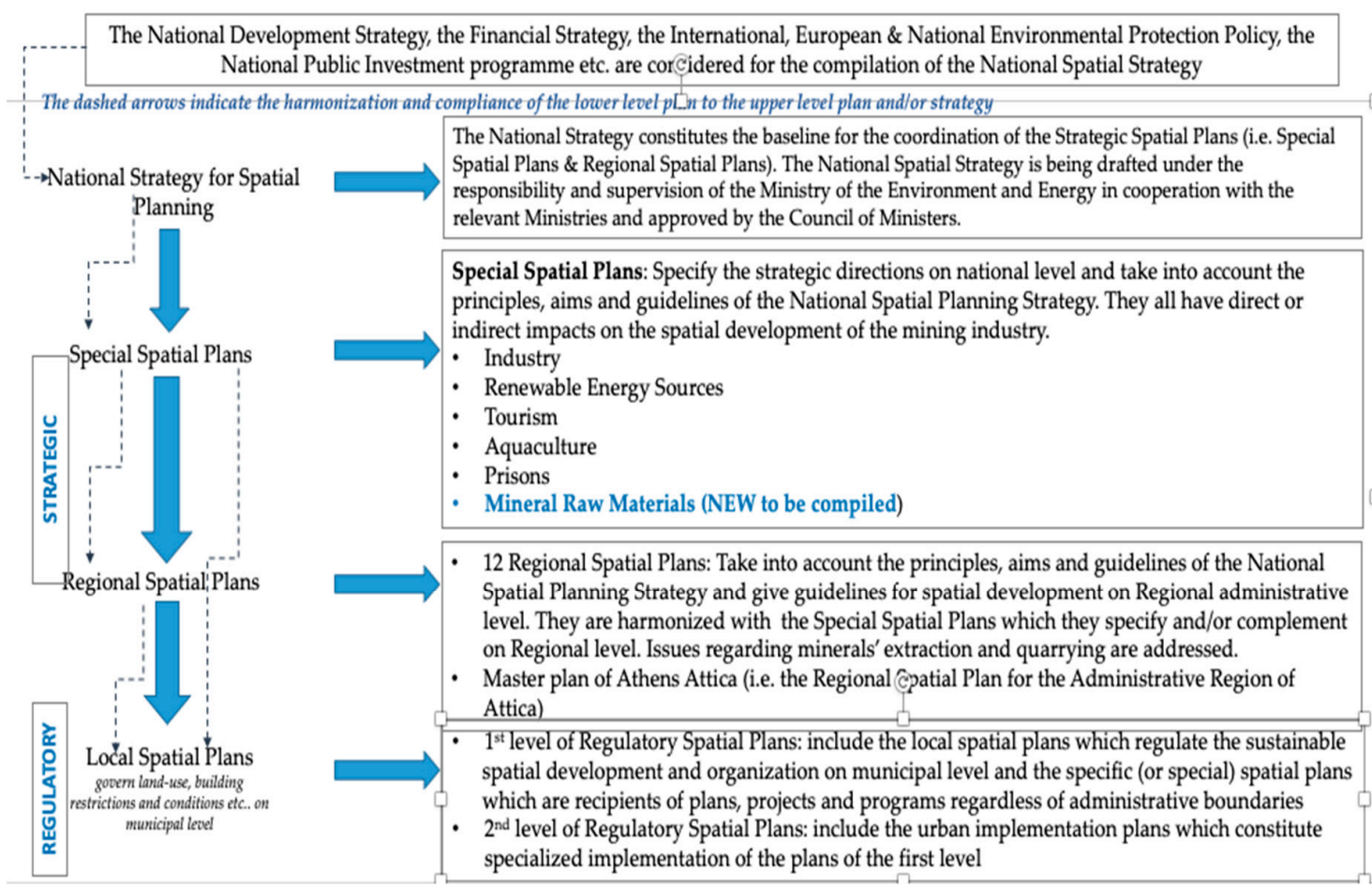

Figure 4. The structure of the Greek Spatial Planning System according to Law 4447/2016 "Spatial planning-sustainable development and other provisions", Source: [41] and authors' own elaboration.

It is worth noting that since the lack of landscape protection was broadly acknowledged before the establishment of the ELC and the need to proceed to relevant regulation, through a variety of 
policies, was evident, the so-called Special Spatial Plans preceding the Greek law that ratified the ELC (Law 3827/2010), clearly set out the need to establish a landscape policy. More specifically:

- The Specific Industrial Spatial Plan looks forward to removing negative impacts on the landscape and aims, among other things, to promote the integration of the environmental component into the spatial structure of activity, notably by promoting organized forms of industrial siting.

- The Special Framework for Renewable Energy Sources (RES), provides for a specific methodology for integrating wind farms into the landscape.

- The Special Framework for Tourism found that preserving and highlighting natural and cultural resources and landscapes, as well as addressing the impacts associated with climate change, are key prerequisites for achieving sustainable tourism, which has a positive effect in synergy with the natural, cultural, economic and social specificities of a region.

It is noteworthy that the General Framework issued in 2008, on an overarching scale from the above mentioned Special Spatial Plans and tracing the strategic directions for an integrated, balanced and harmonious development recognizes that "landscapes... and traditional settlements are not adequately protected in practice due to conflicts with economic interests investing in real estate and the intense housing development trends." [42]

Moreover, in operational terms, the concept of landscape has been incorporated in the Special Spatial Planning Framework for Renewable Energy Sources (SSPF-RES), legislated in 2008 [43] which contains a specific and detailed methodology for integrating renewable energies (wind turbines) into the landscape. Finally, an integrated approach was implemented with the incorporation of landscape policy in the new Regional Spatial Planning Frameworks (RSPFs), which come under the responsibility of the Department of Spatial Planning of the Ministry of Environment and Energy. The new RSPFs are currently in the process of being legislated, and are now called Regional Spatial Plans (RSP).

\subsection{The Greek Response to the European Landscape Convention, Spatial Planning Implications}

The Council of Europe Conference of Ministers responsible for spatial/regional planning (CEMAT) has shown [44] that well-designed spatial planning policies based on balancing social, cultural, economic and environmental needs are essential in order to ensure sustainable long-term growth and exploit the landscape as a strategic component of citizens' quality of life, in accordance with the European Landscape Convention. Through specific guidelines, CEMAT [44] revealed that spatial planning policy can contribute to landscape protection and management, and that landscape policies should be incorporated in spatial planning, as well as in the other sectoral policies which have a direct or indirect impact on the evolution of landscapes.

Greece's participation in the activities of the Council of Europe, in the framework of both CEMAT and the ELC, has been particularly active. Greece ratified the European Landscape Convention by Law $3827 / 2010$ and hosted many international seminars and workshops. What was achieved because of the ratification of the Convention is the inclusion of a chapter on landscape policy and management in the Regional Spatial Planning Frameworks (RSPFs) given their scheduled evaluation and review for the country's 12 Regions (except Attica). This aimed to provide the RSPFs with a comprehensive and specialized approach to landscape issues, to be used for identifying in each Region landscapes of particular significance, regarding which priority will be given to the implementation of coordinated promotion and management actions. Landscape is considered to be environmental and development planning resource representing the country's comparative advantage, while guidelines for landscape management are also provided in the underlying planning (on the Municipal level) [45].

For the first time, the strategic directions of the RSPFs will also include a series of assessments and proposals, concluding in the following: (a) the identification of landscape zones; (b) general policies and guidance on the protection, promotion and sustainable management of landscape as a whole; (c) key priorities and landscape quality targets for each Landscape Zone to be specified in every Region, so as to ensure that all development projects contribute to the achievement of these targets; and (d) 
proposals on minimizing the pressures that distort landscape, and suggested proposals on policies and management measures which should have to be specified in detail in the underlying planning, including in regulatory terms (Local Spatial Plans, Special Spatial Plans, Athens Master Plan, etc.) [45].

Greece is endowed by cultural heritage of great magnitude and rich biodiversity that includes a range of endangered species and ecosystems. The continuous interaction between natural and man-made heritage has contributed to the creation of a mosaic of invaluable landscapes. The character of these landscapes is not static but constantly evolving. However, the period following the 1960s and 1970s contributed mostly to the transformation of these places due to intense urbanization, construction works and residential growth. Since then, the occurring changes have often contributed to the degradation of these landscapes.

Already since the first phase of the implementation of the ELC in Greece, inspiration is sought from practices established in other European countries with a codified institutional framework for the protection of landscape elements [17]. For example, practices were examined such as the background for landscape assessment, focusing on multiple variables, widely used in England and Scotland in studies, either theoretical or practical and applied. Other options regarded landscape mapping (atlases) that allow the creation of a common "dialect", a common terminology on landscape issues, thus supporting the competent authorities in the decision-making regarding the management and protection of the landscape. Nevertheless, no similar measures were adopted yet.

Furthermore, in Greece, the landscape was originally integrated into environmental planning without any interconnection with the spatial planning realm. The role of landscape planning in spatial plans and programs, directly affecting a multitude of quantitative and qualitative factors of the natural and man-made environment, was completely ignored. The State chose, for the environmental components, to adopt an autonomous framework of tools and actions, independent of that of the spatial components, without direct interconnection and interdependence. The cooperation of the authorities responsible for the environment and spatial planning was usually occasional. The inevitable consequence was the ineffectiveness of the adopted measures, the gap between legal commitments and their implementation, but often circumvention, and failure to monitor and control the implementation. This initial aspect has, of course, changed, the natural and cultural components of the landscape are understood through the spatial footprint of culture, whilst, on the other hand, the setting of landscape quality objectives is achieved by their integration into spatial planning.

The ELC boosted the inclusion of landscape policy in spatial planning which is, nowadays, under the responsibility of the General Secretariat of Planning and Urban Environment of the Ministry of Environment and Energy. In the framework of the development of the national spatial policy, the authority was given the mission to deal with the regulation and organization of human activities and functions with rational distribution, structuring and development of natural resources, as well as by coordinating the implementation of development programs on the basis of the principles of sustainable development, competitiveness social cohesion and the quality of life and the environment. Despite this, the institutional and operational implications of landscape planning remain weak. The feature is that both the original Law of spatial planning (Law 2742/99) under which the Regional Spatial Planning Frameworks were revised and the recent planning law (Law 4447/2016), which, both, determine the status of planning policy, does not explicitly refer to landscape policy. Specifically, in the oldest, and prior to the Convention, Law 2742/1999 ("Spatial planning and sustainable development" issued in compliance to the ESDP), the concept of landscape occurs indirectly through the "protection and restoration of the environment, conservation of ecological and cultural reserves and the promotion and highlight of the country's comparative geographic, natural, productive and cultural assets". Similarly, in the law 4546/2018 issued in compliance to the European Directive 2014/89/EU, laying down a framework for Maritime Spatial Planning, no guidance is given either for the management of the marine (seascapes) or the coastal landscapes [15]. However, an indirect reference is made through the definition of the law on Integrated Coastal Zone Management (ICZM) that is described as a dynamic process for the sustainable 
management and use of coastal areas, while estimating the fragile nature of coastal ecosystems and landscapes [15].

The establishment of high-quality landscapes deriving from the feedback relationship that local communities develop with the natural-geographic features of space in the context of socio-economic relations, as these develop at the local, national and international level, is a requirement of modern times but also a necessity of which we become increasingly aware.

\section{Discussion and Recommendations}

The ratification by Greece of the European Landscape Convention incurred during the first years of the economic crisis and the subsequent economic recession and gave new momentum to spatial planning in the country, by adding a qualitative dimension to planning. On the other hand, during the debt crisis that began in 2008 and proved to be a decade-long economic and social crisis, the Greek spatial planning system seriously affected by the economic recession shifted to planning procedures positive to economic investments and the market requirements, limiting in many cases the regulatory character of planning and the spatial planning levels, to facilitate fast-track. Thus, in conditions of economic crisis and social fragmentation, governed by a shift towards a more flexible and neoliberal approach to planning $[46,47]$ the new tools for managing landscape and raising public awareness on it, proved to be necessary to reaffirm ethical values and help build a new attitude of responsibility towards the environment and people, since landscape policy can influence the directions of spatial planning and protect the environment and the Place memory and identity.

In addition to incorporating landscape in spatial planning at the regional level, this was integrated into national-scale spatial planning tools mostly linked to investment opportunities, i.e., in the Special Spatial Planning Frameworks (RSPFs), which are strategic planning documents at the national level and concern, inter alia, the spatial structure of sectors or branches of productive activities and, more generally, sectors of development of national importance. Currently, the revision of the Special Spatial Planning Frameworks (SSPFs) for Tourism, Renewable Energy Sources (RES), Industry, Aquaculture and Detention Facilities is in progress, while a new SSPF for Mineral Raw Materials is under development. In both the new and the revised SSPFs, the concept of landscape will be a key component for the development of each sector, and will also take into account the landscape policy already proposed in the RSPs.

The approach to landscape through the new generation of spatial planning tools (Figure 4), as discussed above, comes to cover, to a great extent, the lack of an integrated approach to landscape policy, thus giving to spatial planning and to the new Regional and Special Spatial Planning Frameworks the role of "catalysts" in addressing the current challenges in landscape-related issues, whilst seeking to balance "human desires" and "conditions for development", especially in the aftermath of the economic crisis. It has now become clear that landscape is a "space regulator", i.e., a parameter to be taken in a systematic way into account by spatial planning processes, promoting the harmonious integration to it of all the changes imposed by socio-economic change and environmental processes. At the same time, through the mutual feedback that exists between landscape and spatial planning, a new dynamic is created for a change in the planning vision, philosophy and inspiration-a change that will allow the preservation of the Greek landscapes that Jacques Lacarrière described as landscapes "of rare perfection and sensitivity (paysages exquis)" [48].

Yet, in addition to the adoption of landscape management directions through the new RSPFs and SSPFs, what is further required is an ongoing effort to create additional landscape tools that will strengthen the landscape dimension of sectoral and spatial policies. Such tools could include the establishment of a Greek Landscape Observatory, in order to pinpoint landscape features at the local level and, at the same time, contribute to the sound management of space; the compilation of a Landscape Atlas for each Region (as happens in France); or even the creation of a National (or Regional) Landscape Fund to finance good landscape management practices, similar to the "Fond Suisse pour le 
Paysage" in Switzerland. Tools of this type are important mechanisms for the implementation of the European Landscape Convention.

Every sectoral policy, as well as landscape policy, is expressed and promoted through the spatial tools and more specifically through the regional and local spatial plans and their directions and measures.

However, the term "direction" has never been elucidated by any relevant law on spatial planning, although it encapsulates this philosophy and predicts plans. This is due to the lack of conceptual definition and the non-specification of the content. Here the concept of "binding" is introduced as a basic component of the above, which can be interpreted differently according to which the gravity and the "regulatory value" of the projects are determined [49].

Particularly, it is clear that the Spatial Plans are strategically oriented by more generic landscape policy guidelines since it is not the role of planning to impose purely regulatory provisions in order to regulate the underlying design. It is also important to clarify that the spatial planning frameworks (national and regional level) have an obligation to direct the underlying design. Despite their non-regulatory (strategic) character, these frameworks bind the underlying design as they provide their mandatory implementation.

\section{Conclusions}

This research paper primarily aimed at positioning landscape as a connecting link between nature and culture. Landscapes reconnect symbolically nature and culture, since they developed due to natural processes in continuous interaction with social and cultural interventions and economic pressures and are major sources of a series of ecosystem services including cultural ones (CES), thus being sources of inspiration, cultural and recreational values. Landscapes and especially cultural landscapes are nowadays comprehended as social-ecological systems, in which social, economic, and environmental components are closely interlinked. This consideration, in combination with the evolution of our understanding of conservation, has apparently influenced the definition of landscape as expressed in the European Landscape Convention (ELC) of the Council of Europe. Based on the literature review, a conclusion is that the ELC marks a transition regarding an environmental and territorial understanding of the concept of landscape and the correlated actions of landscape protection, management and planning.

Data from the Information System of the Council of Europe ELC confirm that the "spatial and regional planning" and the "environmental policy" sectors are the main sectors where landscape considerations are well installed. However, do these two policy realms co-operate in order to achieve an integrated landscape policy with a European territorial perspective?

To explore this, the example of Greece was analyzed. The ratification of the ELC by Greece, originally integrated into environmental planning without any interconnection with the spatial planning realm, finally resulted in a specialized and decentralized—regional—spatial planning approach to the landscape. In each Region, landscapes of particular significance have been identified, so as to be given priority in terms of the implementation of coordinated governance arrangements and management actions. This initiative gave new impetus to spatial planning, as it managed to coordinate a landscape policy able to positively influence the evolving spatial planning paradigm. However, further adaptations are needed, namely the emphasis on the idea to further reconnect natural and cultural capital which is also an already manifested European policy [50], directly related with contemporary conservation and landscape trends which may be essential for the shift from a normative planning to a visionary, forward-thinking, resilient, ecosystem-based and adaptive management-based spatial planning, both on land and on sea. In this sense, the new-generation spatial planning tools (Regional Spatial Plans, RSPs, Special Spatial Plans, SSPs, see Figure 4) and the recent law 4546/2018 for Maritime Spatial Planning should seriously take into account the landscape either terrestrial or marine or even underwater [51], thus ultimately creating the dynamic for a change in the philosophy, inspiration and vision of planning in the country, incorporating its evolutionary perspective and as a consequence an 
evolutionary perspective for landscape itself, viewed as a complex social-ecological system. Nowadays, Regional Spatial Planning Frameworks remain the sole spatial planning tools with extensive reference to landscape management issues. Nevertheless, efficiency requires adaptation to both the recent evolution of the Greek Spatial Planning System and to the new trends in spatial planning, at a global and European scale. Focus on the ecosystems and resilience thinking perspective and the evolutionary trend in spatial planning and governance [52-54] is of paramount importance. It is hopeful that in the aftermath of the economic crisis, a very recent governmental change in Greece upgraded the responsibility of Spatial Planning through the establishment of a competent State Secretary reporting directly to the Prime Minister. This may create the conditions for strategic and forward-thinking planning that will comply with a renewed development model to be followed to balance economic growth and ecosystem-based planning and management, both on land and on sea. An enhanced landscape policy according to the ELC should be prioritized, in this framework.

Summing up, our main conclusion is that landscapes, as viewed and promoted through the ELC represent currently dynamic and complex socio-ecological systems, in other words, organized assemblages of human and non-human life and of natural and cultural heritage and involving complex interrelationships of economic, cultural, institutional and political order. When elaborating spatial and territorial development plans, landscapes should be treated as such and this is to be fully researched by the ELC and its party countries, probably using different case-studies. To this end, considering landscape and related decision-making through the concept of ecosystem services is of paramount importance, since the ecosystem services concept is progressively embedded into decision-making and planning activities.

This can add to spatial planning itself to be more sensitive and adaptive to culture and nature, that is joint to human life in its natural environment, seriously envisaging its historical and identity-related perspective.

Author Contributions: The authors contributed equally to this work.

Funding: This research received no external funding.

Acknowledgments: The authors would like to warmly thank the anonymous reviewers for their precious comments and recommendations to improve the content and shape of this paper.

Conflicts of Interest: The authors declare no conflict of interest.

\section{References}

1. Antrop, M. A brief history of landscape research. In The Routledge Companion to Landscape Studies; Howard, P., Thompson, I., Waterton, E., Atha, M., Eds.; Routledge: Abingdon-on-Thames, UK, 2013.

2. Taylor, C. The making of the English landscape and beyond: Inspiration and dissemination. Landscapes 2005, 6, 96-104. [CrossRef]

3. Menatti, L. Landscape: From common good to human right. Int. J. Commons 2017, 11, 641-683. [CrossRef]

4. Uzun, V.F.; Somuncu, M. Cultural Landscape: An Evaluation from past to present. In Handbook of Research on Methods and Tools for Assessing Cultural Landscape Adaptation; Paulo, A., Eduardo, A., Pedro, A., Eds.; University of Lisbon: Lisbon, Portugal, 2018; pp. 1-27. [CrossRef]

5. Leser, H.; Löffler, J. Landschaftsökologie; Ulmer: Stuttgart, Germany, 1997.

6. Moreira, F.; Queiroz, A.I.; Aronson, J. Restoration principles applied to cultural landscapes. J. Nat. Conserv. 2006, 14, 217-224. [CrossRef]

7. Linnell, J.D.; Kaczensky, P.; Wotschikowsky, U.; Lescureux, N.; Boitani, L. Framing the relationship between people and nature in the context of European conservation. Conserv. Biol. 2015, 29, 978-985. [CrossRef] [PubMed]

8. Hermann, A.; Schleifer, S.; Wrbka, T. The concept of ecosystem services regarding landscape research: A review. Living Rev. Landsc. Res. 2011, 5, 1-37. [CrossRef]

9. Naveh, Z. Interactions of landscapes and cultures. Landsc. Urban Plan. 1995, 32, 43-54. [CrossRef]

10. Rössler, M. World Heritage cultural landscapes: A UNESCO flagship programme 1992-2006. Landsc. Res. 2006, 31, 333-353. [CrossRef] 
11. Berkes, F.; Colding, J.; Folke, C. (Eds.) Navigating Social-Ecological Systems: Building Resilience for Complexity and Change; Cambridge University Press: Cambridge, UK, 2003.

12. Höchtl, F.; Lehringer, S.; Konold, W. "Wilderness": What it means when it becomes a reality-A case study from the southwestern Alps. Landsc. Urban Plan. 2005, 70, 85-95. [CrossRef]

13. Vos, W.; Meekes, H. Trends in European cultural landscape development: Perspectives for a sustainable future. Landsc. Urban Plan. 1999, 46, 3-14. [CrossRef]

14. Mace, G.M. Whose conservation? Science 2014, 345, 1558-1560. [CrossRef]

15. Kyvelou, S. Toward quality marine landscape plans. In Proceedings of the 22nd Council of Europe Meeting of the Workshops for the implementation of the European landscape Convention and International Congress "Water, Landscape and Citizenship in the Face of Global Change", Seville, Spain, 14-16 March 2019.

16. Déjeant-Pons, M. The European Landscape Convention. Landsc. Res. 2006, 31, 363-384. [CrossRef]

17. De Montis, A. Impacts of the European Landscape Convention on national planning systems: A comparative investigation of six case studies. Landsc. Urban Plan. 2014, 124, 53-65. [CrossRef]

18. Gourgiotis, A. La gestionopérationnelle du paysage à travers les outils de l'aménagement du territoire. In Proceedings of the 13th Council of Europe Meeting of the Workshops for the Implementation of the European Landscape Convention, Cetinje, Montenegro, 2-3 October 2013; Edition Council of Europe No. 100; pp. 327-337.

19. Council of Europe. The European Landscape Convention; Council of Europe: Strasbourg, France, 2000.

20. Roe, M.H. The European Landscape Convention: A revolution in thinking about cultural landscapes. J. Chin. Landsc. Archit. 2007, 23, 10-15. (In Chinese with English Abstract)

21. Chueca, P. Estudiocomparativo de las politicas de paisajeenFrancia, losPaisesBayos y Suiza [Comparative analysis of landscape policies in France, Netherlands and Switzerland]. In Centro de EstudiosPaisaje y Territorio, Ed., La situacióndel. PaisajeenEspaña. Líneas para la aplicación y desarrollo del ConvenioEuropeo del Paisaje [The status of landscape in Spain. Guidelines for the application and development of the European Landscape Convention]; Centro de EstudiosPaisaje y Territorio, Ed.; University of Andalusia Press: Seville, Spain, 2008; pp. 2-4. (In Spanish)

22. Voghera, A. The implementation of the European landscape convention in different countries. In Proceedings of the Effects on Landscape Living Landscape, Florence, Italy, 18-19 October 2010; pp. 386-398.

23. ESPON Liveland Project, Final Report. Available online: https://www.espon.eu/programme/projects/espon2013/targeted-analyses/liveland-liveable-landscapes-key-value-sustainable (accessed on 19 June 2019).

24. Herlin, I.S. Exploring the national contexts and cultural ideas that preceded the Landscape Character Assessment method in England. Landsc. Res. 2016, 41, 175-185. [CrossRef]

25. Fairclough, G.; Herlin, I.S.; Swanwick, C. (Eds.) Routledge Handbook of Landscape Character Assessment, Current Approaches to Characterisation and Assessment; Routledge: London, UK, 2018; p. 312. [CrossRef]

26. Landscape Observation (Observatori di Paisage). Generalitat de Catalunya. Departament de PoliticaTeritorial I ObresPubliques. Council of Europe. July 2006. Available online: www.catpaisatge.net. (accessed on 26 July 2019).

27. Zoido-Naranjo, F. Landscape and spatial planning policies. In Council of Europe, Landscape and Sustainable Development: Challenges of the European Landscape Convention; Council of Europe Publishing: Strasbourg, France, 2006; pp. 54-79.

28. Cartei, G.F. The Implementation of the European Landscape Convention and Public Participation. Eur. Public Law 2012, 18, 269-282.

29. Phillips, A.; Clarke, R. Our Landscape from a Wider Perspective. In Countryside Planning: New Approaches to Management and Conservation; Earthscan Bishop, K., Phillips, A., Eds.; Routledge: Oxon, UK, 2004; pp. $49-67$.

30. Selman, P. Centenary paper: Landscape planning-preservation, conservation and sustainable development. Town Plan. Rev. 2010, 81, 381-406. [CrossRef]

31. Kidd, S. Landscape planning: Reflections on the past, directions for the future. In The Routledge Companion to Landscape Studies; Howard, P., Thompson, I., Waterton, E., Eds.; Routledge: Oxon, UK, 2013; pp. 366-382.

32. Brunetta, G.; Voghera, A. Evaluating landscape for shared values: Tools, principles, and methods. Landsc. Res. 2008, 33, 71-87. [CrossRef]

33. Herlin, I.S. New challenges in the field of spatial planning: Landscapes. Landsc. Res. 2004, 29, $399-411$. [CrossRef]

34. Tomkinson, J.L. Travellers' Greece: Memories of Enchanted Land; Anagnosis: Athens, Greece, 2002; p. 608. 
35. Gourgiotis, A.; Tsilimingas, G. The new identity of Greek landscape. Instruments for landscape sustainable management [In Greek: H nea taftotita tou ellinikou topiou: Michanismi kai regalia gia tin diachirisi tou]. In Regional Planning and Spatial Analysis Issues: Methods, Tools and Support Systems; Rontos, K., Ed.; G. Benou: Athens, Greece, 2010.

36. Mpeopoulos, N. Thoughts and questions from the emergence of public interventions in the landscape through agri-environmental measures [in Greek: Skepsis kai erotimata apo tin emfanisidimosionparemvaseonstotopiomesometronagroperibalontikis]. In Search of the Greek Landscape, Proceedings of the 1st Workshop under the Hellenic Landscape Conservation and Management Program, 21-22 May 2009; Papagianis, T., Sorotou, A., Eds.; Med-INA, Agricultural University of Athens and WWF Hellas: Athens, Greece, 2010; pp. 53-64.

37. Parpairis, A. The landscape is a basic component of spatial planning [To topio vasiki sinistosa tou chorikou sxediasmou]. In Theory and Politics of the Landscape: Greek and French Experiences; Beriatos, E., Ed.; Dep. of Planning and Regional Development, University of Thessaly: Volos, Greece, 2007.

38. DATAR. Paysages Photographies: La Mission Photographique de la Datar: Travaux en Cours 1984/1985; Ed.Hazan: Paris, France, 1985; p. 517.

39. Vlantou, A. The Landscape as Environmental Good: Incompatibility between the Right to Protection and the Reality. [In Greek To Topio os Perivalontiko Agatho: Asymvatotita Metaxy Dikaiouprostasias Kai Pragmatikotitas]. Available online: http://www.nomosphysis.org.gr (accessed on 26 July 2019). (In Greek)

40. Kousidonis, T.C. The Organization of Space and Planning-Planning: An. Introduction; TEE. Z' Short Term Seminar Extraordinary Cycle: Volos, Greece, 2007; Available online: http://library.tee.gr/digital/kma/kma_ m1418/kma_m1418_kousidonis.pdf (accessed on 26 July 2019).

41. Hatzilazaridou, A. Presentation at the Workshop on Mineral and land use legislation and policies, Institute of Geology and Mineral Exploration, Athens, Ministry of Environment and Energy, Athens, Greece, 9 November 2018.

42. Official Government Gazette, General Framework for Spatial Planning and Sustainable Development. 2008. A' 128. Available online: http://www.ypeka.gr/LinkClick.aspx?fileticket=znJpFQj917U\%3d\&tabid=513\& language=el-GR (accessed on 26 July 2019).

43. Official Government Gazette Special Framework for Spatial Planning and Sustainable Development for Renewable Energy Sources and Strategic Environmental Impact Assessment'. 2008. B' 2464. Available online: http://www.ypeka.gr/LinkClick.aspx?fileticket=zkMN5DrZKKo\%3d\&tabid=513 (accessed on 26 July 2009).

44. CEMAT, Guiding Principles for Sustainable Spatial Development of the European Continent adopted at the 12th Session of the European Conference of Ministers responsible for Regional Planning, Hanover, Germany, 7-8 September 2000. Available online: https://rm.coe.int/1680700173 (accessed on 26 July 2019).

45. Gourgiotis, A. The Contribution of the Council of Europe to Spatial Planning and Landscape; Texts of Urban Planning, Spatial Planning and Development; Dept. of Planning and Regional Development, University of Thessaly: Volos, Greece, 2014; Volume 19, pp. 38-57. (In Greek)

46. Papageorgiou, M. Spatial planning in transition in Greece: A critical overview. Eur. Plan. Stud. 2017, 25, 1818-1833. [CrossRef]

47. Giannakourou, G.; Kafkalas, G. Re-examining spatial planning in times of crisis: Necessity, content and conditions of reform. In Competitiveness for Development. Policy proposals; Hellenic Bank Association: Athens, Greece, 2014; pp. 511-522. (In Greek)

48. Greekscapes. Aerial Photography Atlas of Greek Landscapes. Modern Greek Cultural Landscape: Theoretical Framework, Methodology, Synthetic Observations; John S. Latsis Foundation, Research Programme financed by John S. Latsis Foundation, 2008-2010; Department of Geography, Harokopion University: Kallithea, Greece, 2010.

49. Chaindarlis, M. The Legal Spatial Tools of Strategic Nature; Nomiki Vivliothiki: Athens, Greece, 2017; p. 168, ISBN 978-960-622-365-5. (In Greek)

50. Paracchini, M.L.; Zingari, P.C.; Blasi, C. (Eds.) Reconnecting Natural and Cultural Capital Contributions from Science and Policy; Publications Office of the European Union: Luxembourg, 2018.

51. Argyropoulos, V.; Stratigea, A. Sustainable Management of Underwater Cultural Heritage: The Route from Discovery to Engagement-Open Issues in the Mediterranean. Heritage 2019, 2, 98. [CrossRef]

52. Davoudi, S.; Zaucha, J.; Brooks, E. Evolutionary resilience and complex lagoon systems. Integr. Environ. Assess. Manag. 2016, 12, 711-718. [CrossRef] [PubMed] 
53. Beunen, R.; Hagens, J.E. The Use of the Concept of Ecological Networks in Nature Conservation Policies and Planning Practices. Landsc. Res. 2009, 34, 563-580. [CrossRef]

54. Beunen, R.; Van Assche, K. Contested delineations: Planning, law and the governance of protected areas. Environ. Plan. A 2013, 45, 1285-1301. [CrossRef]

(C) 2019 by the authors. Licensee MDPI, Basel, Switzerland. This article is an open access article distributed under the terms and conditions of the Creative Commons Attribution (CC BY) license (http://creativecommons.org/licenses/by/4.0/). 